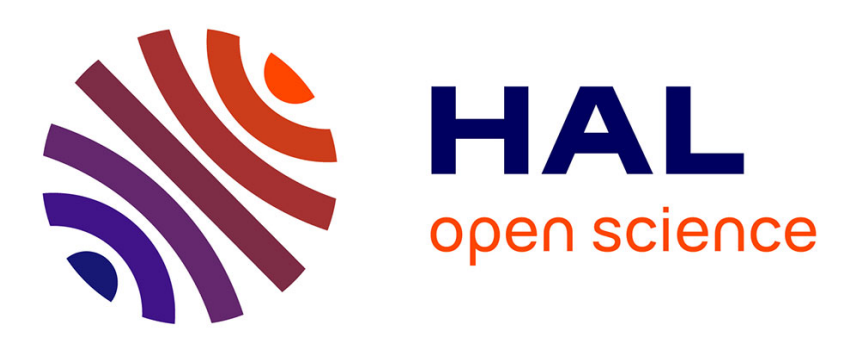

\title{
Tuning the structure and the properties of dithiafulvene metalla-assembled tweezers
}

Maksym Dekhtiarenko, Serhii Krykun, Vincent Carré, Frédéric Aubriet, David Canevet, Magali Allain, Zoia Voitenko, Marc Sallé, Sébastien Goeb

\section{- To cite this version:}

Maksym Dekhtiarenko, Serhii Krykun, Vincent Carré, Frédéric Aubriet, David Canevet, et al.. Tuning the structure and the properties of dithiafulvene metalla-assembled tweezers. Organic Chemistry Frontiers, 2020, 7 (15), pp.2040-2046. 10.1039/D0QO00641F . hal-02916232

\section{HAL Id: hal-02916232 \\ https://hal.science/hal-02916232}

Submitted on 14 Dec 2020

HAL is a multi-disciplinary open access archive for the deposit and dissemination of scientific research documents, whether they are published or not. The documents may come from teaching and research institutions in France or abroad, or from public or private research centers.
L'archive ouverte pluridisciplinaire HAL, est destinée au dépôt et à la diffusion de documents scientifiques de niveau recherche, publiés ou non, émanant des établissements d'enseignement et de recherche français ou étrangers, des laboratoires publics ou privés. 


\section{ARTICLE}

\section{Tuning the structure and the properties of dithiafulvene metalla- assembled tweezers}

Received 00th January 20xx, Accepted 00th January 20xx DOI: $10.1039 / x 0 x \times 00000 x$

\author{
Maksym Dekhtiarenko, ${ }^{\mathrm{a}, \mathrm{b}}$ Serhii Krykun, ${ }^{\mathrm{a}, \mathrm{b}}$ Vincent Carré, ${ }^{\mathrm{c}}$ Frédéric Aubriet, ${ }^{\mathrm{c}}$ David Canevet, ${ }^{\mathrm{a}}$ Magali \\ Allain, ${ }^{a}$ Zoia Voitenko, ${ }^{b}$ Marc Sallé*a and Sébastien Goeb*a
}

\section{Introduction}

The coordination-driven strategy has been successfully used to construct a considerable variety of discrete architectures with very high yields. ${ }^{1,2}$ One reason for this success, lies on the high degree of predictability in the geometry of the resulting selfassembled structures. ${ }^{3}$ On this basis, more and more complex systems have been produced, including chiral ${ }^{4-6}$, heteroleptic ${ }^{7-9}$ and interlocked ${ }^{10-12}$ ones. Those self-assembled discrete structures generally include a cavity, ${ }^{13}$ and their host properties have been widely studied to target various applications (e.g. depollution, ${ }^{14}$ drug delivery, ${ }^{15}$ catalysis ${ }^{16-18}$ and storage of reactive molecules ${ }^{19}$ ). Nevertheless, for most of these applications, there is an important need for controlling the intensity of the host-guest interaction, ${ }^{20}$ which implies designing stimuli-responsive architectures. ${ }^{21-24}$ On this basis, we described the preparation and properties of a series of redoxactive rings $^{25}$ and cages $^{26-31}$ constructed from the tetrathiafulvalene (TTF) moieties and some of its derivatives. We also recently depicted the efficiency of the 9-(1,3-dithiol-2ylidene)fluorene (DTF)-based ligands, in generating selfassembled discrete structures, be they rings ${ }^{32}$, tweezers ${ }^{33}$ or cages. ${ }^{34}$ The DTF moiety can be oxidized reversibly at low potential to the corresponding radical cation, ${ }^{35,36}$ a species which is prone to form mixed valence or $\pi$-dimer species under specific conditions. This driving force can be exploited to control, reversibly, the release of a guest compound thanks to a redox driven dimerization process. ${ }^{33}$

\footnotetext{
a. Laboratoire MOLTECH-Anjou, UMR CNRS 6200, UNIV Angers, SFR MATRIX, 2 Bd Lavoisier, 49045 Angers Cedex, France.

E-mails: marc.salle@univ-angers.fr; sebastien.goeb@univ-angers.fr

b. Taras Shevchenko National University of Kyiv, 64/13 Volodymyrska st., Kyiv 01033, Ukraine

c. LCP-A2MC, FR 3624, Université de Lorraine, ICPM, 1 Bd Arago, 57078 Metz Cedex 03, France

+ Electronic Supplementary Information (ESI) available. See

DOI: $10.1039 / x 0 \times x 00000 x$
}

We report herein that the shape, the redox and the binding properties of coordination-driven self-assembled metalla-cycles constructed from ditopic DTF based ligands and the cis$\operatorname{Pd}(d p p f)(\mathrm{OTf})_{2} \quad$ complex $\quad\left(d p p f \quad=\quad 1,1^{\prime}\right.$-bis(diphenylphosphino)ferrocene; OTf = trifluoromethanesulfonate), can be efficiently and readily tuned by a simple change from a 4-pyridyl coordinating unit to a 3-pyridyl one.

\section{Results and discussion}

We already reported that the self-assembly of the L4Pyr ligand with cis- $\mathrm{Pd}(\mathrm{dppf})(\mathrm{OTf})_{2}$ in dichloromethane at $40{ }^{\circ} \mathrm{C}$ converges to a single symmetrical $\mathrm{M}_{2} \mathrm{~L}_{2}$ discrete species (Scheme 1 left). ${ }^{32}$ In the present study, we applied a similar synthetic protocol to L3Pyr (Scheme 1 right). The presence of the 3-pyridyl unit leads to a more complex ${ }^{1} \mathrm{H}$ NMR spectrum than the one obtained from L4Pyr (Figure 2). Nevertheless, all aromatic signals could be attributed using a COSY experiment (Figure S2). In particular, all signals of pyridyl proton in $\mathbf{P d}_{\mathbf{2}} \mathbf{L} \mathbf{3} \mathbf{P y r}_{\mathbf{2}}$ are upfield shifted compared to the free L3Pyr ligand, except $\mathrm{H}_{6}$ (Figure 1a). This global observation is assigned to the shielding effect promoted by the phenyl rings from the $d p p f$ coligand, which is compensated in the case of $\mathrm{H}_{6}$ by coordination to the metal. The presence of only one discrete species is confirmed by ${ }^{1} \mathrm{H}$ DOSY NMR experiment (Figure $1 \mathrm{c}$ and S3). The latter shows a single set of signals with a diffusion coefficient of $D=4.96 \times 10^{-10} \mathrm{~m}^{2} . \mathrm{s}^{-}$ 1 , a value which is very similar to the one measured for the $\mathbf{P d}_{\mathbf{2}} \mathbf{L}_{\mathbf{4}} \mathbf{P y r}_{\mathbf{2}}$ metalla-cycle (Figure $1 \mathrm{c}^{\prime}$ ). This observation suggests that the self-assembled structure obtained from L3Pyr is similar in size to the one of $\mathbf{P d}_{\mathbf{2}} \mathbf{L} \mathbf{4} \mathbf{P y r}_{\mathbf{2}}$. The corresponding estimated hydrodynamic radius is of $c a 10 \AA$, as extracted from the StokesEinstein equation $(T=298 \mathrm{~K}), 37,38$ a value which is consistent with the formation of a $M_{2} L_{2}$ architectures as in the case of $\mathbf{P d}_{\mathbf{2}} \mathrm{L}_{\mathbf{P}} \mathrm{Pyr}_{2}{ }^{32}$ 


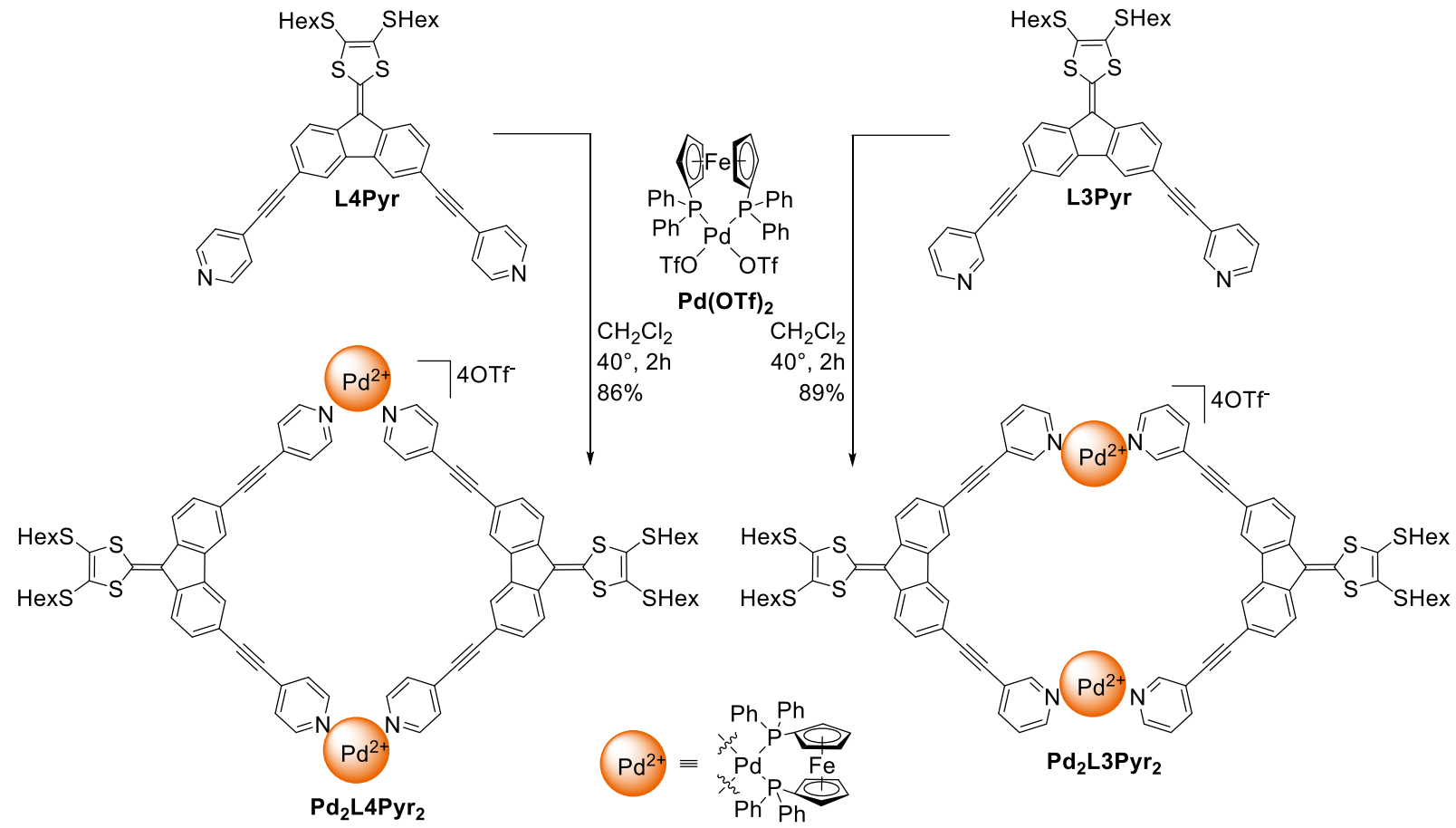

Scheme 1. Synthesis of metalla-macrocycles $\mathbf{P} \mathbf{d}_{\mathbf{2}} \mathbf{L} \mathbf{4} \mathbf{P y r}_{\mathbf{2}}{ }^{32}$ and $\mathbf{P} \mathbf{d}_{\mathbf{2}} \mathbf{L} \mathbf{3} \mathbf{P y r} \mathbf{2}_{\mathbf{2}}$

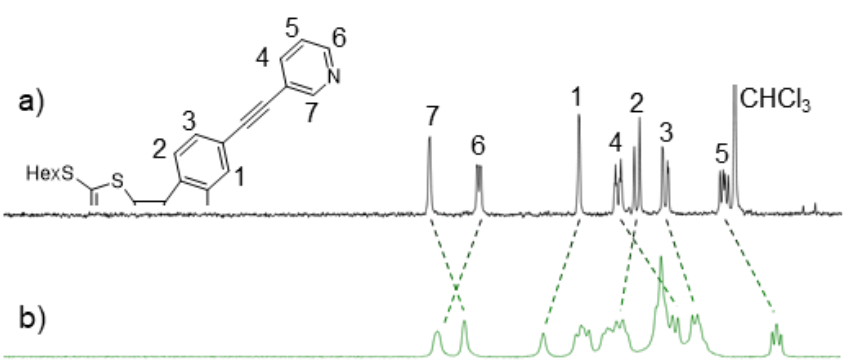

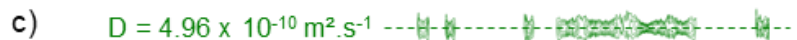

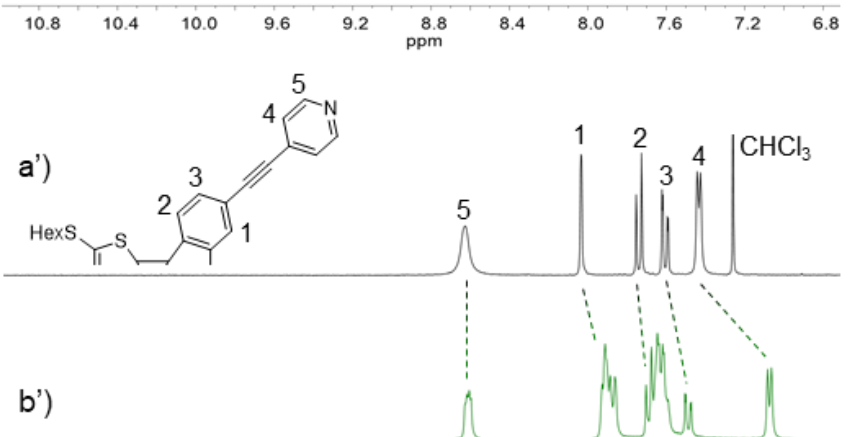

c') $\quad \mathrm{D}=5.03 \times 10^{-10} \mathrm{~m}^{2} \cdot \mathrm{s}^{-1} \cdots \cdots$

$\begin{array}{llllllllllll}10.8 & 10.4 & 10.0 & 9.6 & 9.2 & \begin{array}{r}8.8 \\ \mathrm{ppm}\end{array} & 8.4 & 8.0 & 7.6 & 7.2 & 6.8\end{array}$

Fig. $1^{1} \mathrm{H}$ NMR spectra (aromatic region) of ligands L3Pyr (a) and L4Pyr (a') in CDCl metalla-macrocycles $\mathbf{P d}_{2} \mathbf{L}^{3} \mathbf{P y r}_{2}(\mathrm{~b})$ and $\mathbf{P d}_{2} \mathbf{L}_{\mathbf{P}} \mathbf{P y r}_{2}\left(\mathrm{~b}^{\prime}\right)$ in $\mathrm{CD}_{2} \mathrm{Cl}_{2}$, and corresponding ${ }^{1} \mathrm{H}$ NMR DOSY spectra $\left(c\right.$ and $\left.c^{\prime}\right)$ related to $(b)$ and $\left(b^{\prime}\right)$.

The stoichiometry of the self-assembly $\mathbf{P d}_{\mathbf{2}} \mathbf{L} \mathbf{3} \mathbf{P} \mathbf{Y r} \mathbf{2}_{\mathbf{2}}$ was confirmed by high-resolution ESI-FTICR-MS spectrometry (Figure S4). In addition to signals of the expected $\mathrm{M}_{2} \mathrm{~L}_{2}$ molecular clip $\left[\mathbf{P d}_{\mathbf{2}} \mathbf{L} \mathbf{3} \mathbf{P y r}_{\mathbf{2}}-\mathbf{2 O T f}\right]^{2+} ; \mathrm{m} / \mathrm{z}=1510.667$ ), peaks corresponding to higher molecular masses were observed despite variations carried out on the instrumental conditions, the concentration $\left(10^{-5} \mathrm{M}<\mathrm{C}<10^{-3} \mathrm{M}\right)$ and the solvent. Taken into account the above DOSY NMR data, these experiments suggest aggregation of the starting $\mathrm{M}_{2} \mathrm{~L}_{2}$ metalla-cycle upon ESI. Such behavior is known in the literature with soft ionization conditions ${ }^{39}$ and was also observed in the case of the $\mathbf{P d}_{\mathbf{2}} \mathbf{L} \mathbf{4} \mathbf{P y r}_{\mathbf{2}}$ analogue. ${ }^{32}$

Unfortunately, attempts to grow single crystals of $\mathbf{P d}_{\mathbf{2}} \mathbf{L} \mathbf{3} \mathbf{P y r}_{\mathbf{2}}$ suitable for X-ray analysis were unsuccessful. Theoretical calculations using the $\mathrm{MM}+$ model were undertaken and the results compared to similar experiments carried out for $\mathbf{P d}_{\mathbf{2}} \mathbf{L} \mathbf{4} \mathbf{P y r} \mathbf{2}_{\mathbf{2}}$ (Figure 2). The calculated $\mathbf{P} \mathbf{d}_{\mathbf{2}} \mathbf{L} \mathbf{4} \mathbf{P y r} \mathbf{2}_{\mathbf{2}}$ structure (Figure 2a) is fully consistent with the one observed in the corresponding by X-ray crystallography (Figure S8c). In particular, a dihedral angle of ca. $80^{\circ}$ between both fluorenyl mean planes, and an intramolecular $S \cdots S$ distance between facing dithiole rings of $c a .15 \AA$, were found, and these values are very close to those observed in the crystal. Importantly, switching from a 4-pyridyl coordinating unit to a 3-pyridyl one, drastically modifies the shape of the metalla-clip. The metal coordination in the meta position of the pyridyl groups in $\mathbf{P d}_{\mathbf{2}} \mathbf{L} \mathbf{3 P y r}$, results in a significant conformational change with much closer electroactive units. In particular, $\mathbf{P d}_{\mathbf{2}} \mathbf{L} \mathbf{3 P y r}$ shows a dihedral angle between both fluorenyl units of $c a .27^{\circ}$ and a $S \cdots S$ distance of $c a .8 .5 \AA$.

The electrochemical properties of the metalla-clip $\mathbf{P d}_{2} \mathbf{L} 3 \mathbf{P y r}_{\mathbf{2}}$ were studied by cyclic voltammetry (CV) in $\mathrm{CH}_{3} \mathrm{CN} / \mathrm{CH}_{2} \mathrm{Cl}_{2}$ and compared to the previously described $\mathbf{P d}_{\mathbf{2}} \mathbf{L} \mathbf{4} \mathbf{P y r}_{\mathbf{2}}$ homolog ${ }^{32}$ (Figure 3a). Both L4Pyr and L3Pyr ligands exhibit one reversible redox wave, centered on the DTF moiety at $\mathrm{E}^{\mathrm{ox}}=0.56$ and $0.46 \mathrm{~V}$ vs $\mathrm{Fc} / \mathrm{Fc}^{+}$respectively. One reversible oxidation is also observed for the DTF moieties in $\mathbf{P d}_{\mathbf{2}} \mathbf{L} \mathbf{4} \mathbf{P y r}_{\mathbf{2}}\left(\mathrm{E}_{1}{ }^{\mathrm{ox}}=0.59 \mathrm{~V}\right.$ vs $\mathrm{Fc} / \mathrm{Fc}^{+}$) which is followed by oxidation of the ferrocene moieties 

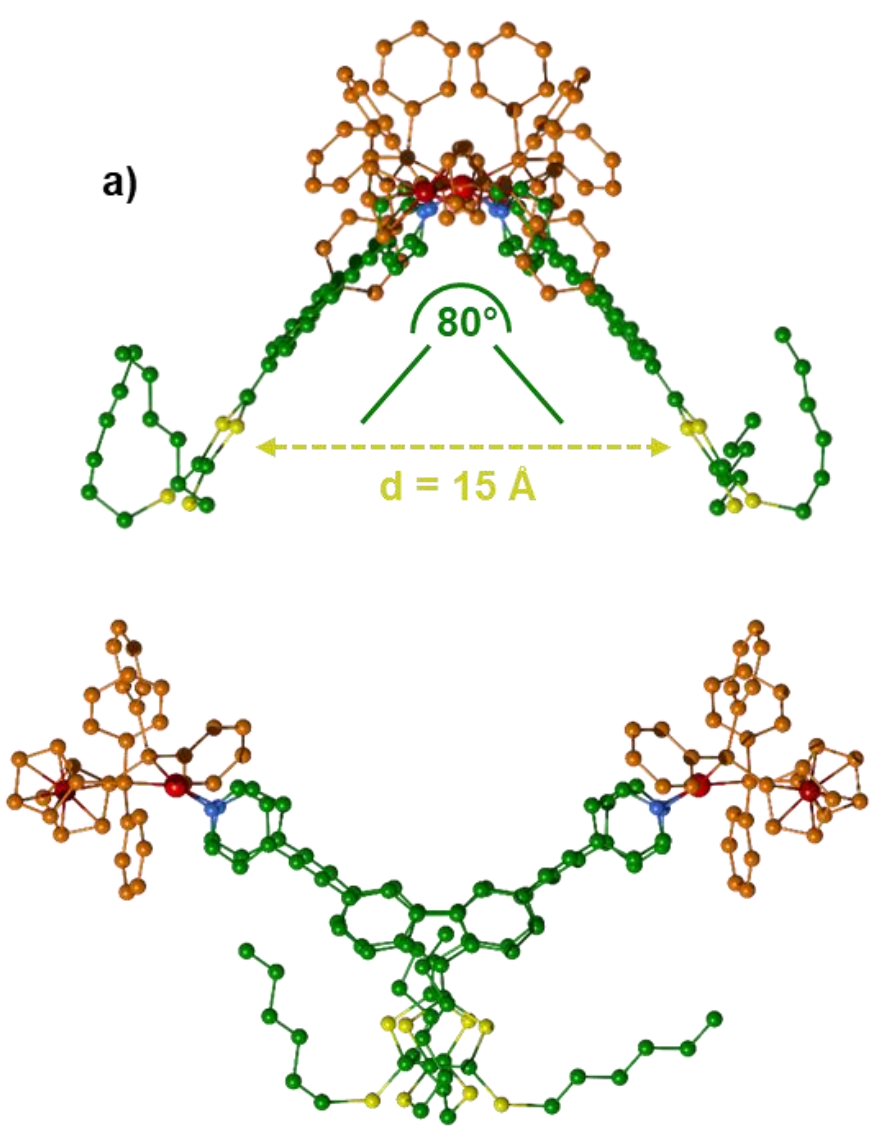

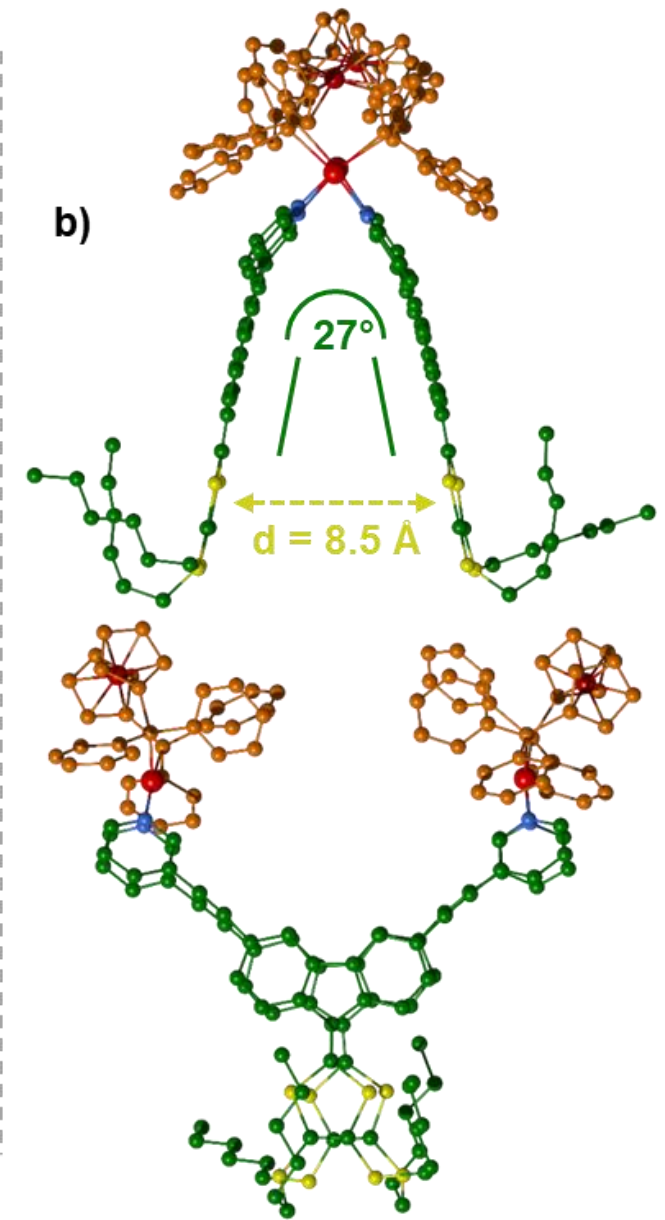

Fig. 2 Molecular force field (MM+) model of tweezers $\mathbf{P d}_{\mathbf{2}} \mathbf{L} \mathbf{4} \mathbf{P y r} \mathbf{P}_{\mathbf{2}}(\mathrm{a})$ and $\mathbf{P d}_{\mathbf{2}} \mathbf{L} \mathbf{3} \mathbf{P y r} \mathbf{P}_{\mathbf{2}}(\mathrm{b})$

at $\mathrm{E}_{2} \mathrm{ox}=0.82 \mathrm{~V}$ vs $\mathrm{Fc} / \mathrm{Fc}^{+}$. This observation indicates that both DTF ligands are electronically equivalent and independent in $\mathbf{P d}_{\mathbf{2}} \mathbf{L}_{\mathbf{4}} \mathbf{P y r}_{\mathbf{2}}$. A striking different behavior is observed for tweezer $\mathbf{P d}_{\mathbf{2}} \mathbf{L} \mathbf{3} \mathbf{P y r}_{\mathbf{2}}$. The $\mathrm{CV}$ of the latter exhibits a splitting of the redox wave corresponding to the DTF units, with 2 reversible oxidations occurring at $\mathrm{E}_{1}{ }^{\mathrm{ox}}=0.49 \mathrm{~V}$ and $\mathrm{E}_{2}{ }^{\mathrm{ox}}=0.63 \mathrm{~V} \mathrm{vs} \mathrm{Fc} / \mathrm{Fc}^{+}$, suggesting that both tips of the tweezer do not behave independently. Such splitting has already been reported in the case of molecular tweezers bearing TTF $^{40}$ and more recently with DTF tips, ${ }^{33}$ and was ascribed to the formation of mixedvalence and $\pi$-dimer species upon oxidation. The abovementioned estimated distance of $8.5 \AA$ a between both panels in $\mathbf{P d}_{\mathbf{2}} \mathbf{L} \mathbf{3} \mathbf{P y r}_{\mathbf{2}}$ should in principle allow the sandwiching of a planar aromatic species between both tips, 41,42 including a selfintercalation of two molecular tweezers if no other species is present in solution. This was confirmed by a concentrationdependent CV study of $\mathbf{P d}_{\mathbf{2}} \mathbf{L} \mathbf{3} \mathbf{P y r}_{\mathbf{2}}$, which shows the disappearance of the splitting phenomenon upon diluting the solution from $\mathrm{C}=10^{-3} \mathrm{M}$ to $\mathrm{C}=6.25 \times 10^{-5} \mathrm{M}$ (Figures $3 \mathrm{c}, \mathrm{d}$ ). Such behavior is similar to the one reported by $E$. Levillain and $P$. Hudhomme for TTF-based molecular clips. ${ }^{40}$ Thanks to the modelling of cyclic voltammetry experiments, these authors could demonstrate that the stepwise oxidation process follows a square scheme involving both neutral and radical cation species, which interact either inside or outside the cavity (Figure S5a). This difference of the CV behavior between $\mathbf{P d}_{\mathbf{2}} \mathbf{L} \mathbf{3} \mathbf{P y r}_{\mathbf{2}}$ and $\mathbf{P d}_{\mathbf{2}} \mathbf{L} \mathbf{4} \mathbf{P y r}_{\mathbf{2}}$, is therefore correlated to the distance separating both tips of the tweezer: whereas $\mathbf{P d}_{\mathbf{2}} \mathbf{L} \mathbf{3} \mathbf{P y r}_{\mathbf{2}}$ can bind a planar guest in the cavity through the simultaneous contribution of

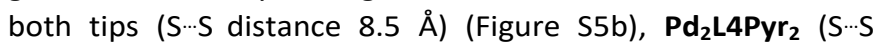
distance $15 \AA$ A) cannot.

Based on those electrochemical experiments and geometrical optimizations, it appears that metalla-clip $\mathbf{P d}_{\mathbf{2}} \mathbf{L} \mathbf{3} \mathbf{P y r}_{\mathbf{2}}$ provides a cavity suitable for guest encapsulation. Additional cyclic voltammetry experiments were therefore carried out to monitor the host-guest interaction process, in presence of 9dicyanomethylene-2,4,7-trinitrofluorene (DCTNF), an electrodeficient planar aromatic compound (Figure 3b). Interestingly, the addition of an increasing amount of DCTNF into a solution of $\mathbf{P d}_{\mathbf{2}} \mathbf{L} \mathbf{3} \mathbf{P y r}_{\mathbf{2}}$ shifts the first oxidation process to higher potential with the disappearance of the wave splitting. This suggests the intercalation of the DCTNF unit between both electron-rich DTF tips, which prevents therefore the above-mentioned selfintercalation process of two oxidized metalla-clips to occur. Moreover, the splitting observed during the reduction process of the oxidized molecular tweezer also disappears in the hostguest system (Figure $3 \mathrm{~b}$ ), ruling out a guest release phenomenon upon oxidation, a behavior that we recently 

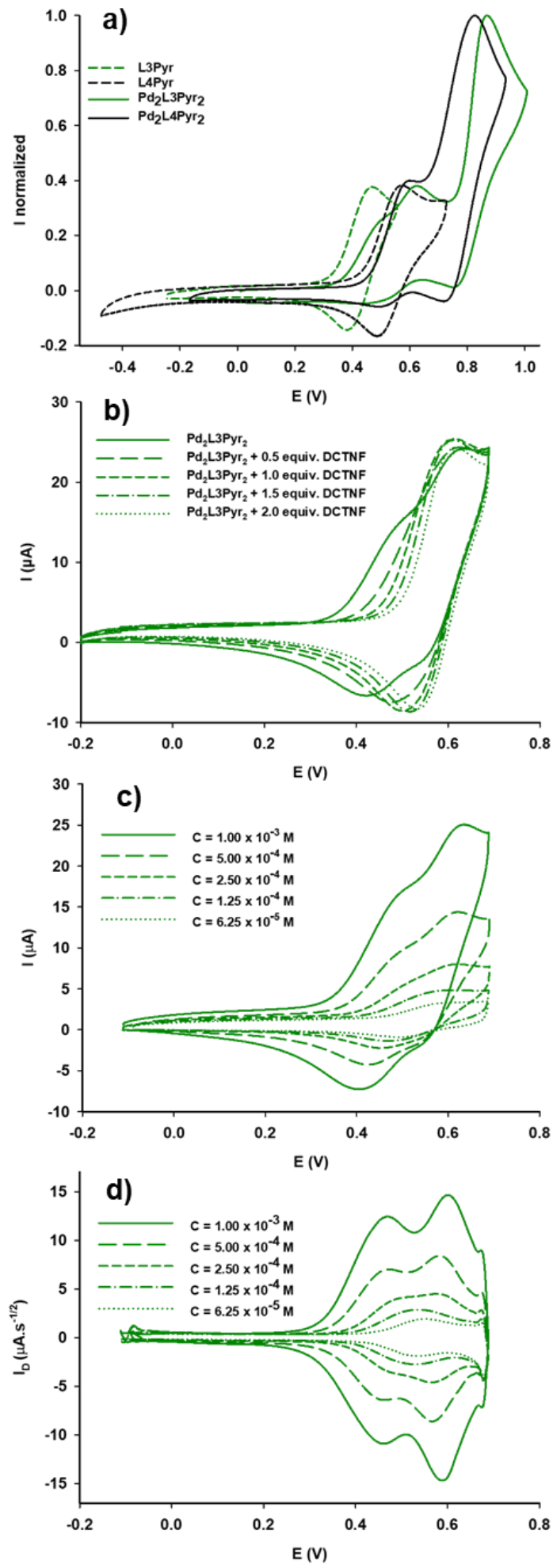

Fig. 3 Cyclic voltammograms $\left(\mathrm{CH}_{3} \mathrm{CN} / \mathrm{CH}_{2} \mathrm{Cl}_{2}(\mathrm{v} / \mathrm{v} 1 / 1), 0.1 \mathrm{MnBu} \mathrm{NPF}_{6}, 100 \mathrm{mV} \cdot \mathrm{s}^{-1}\right.$

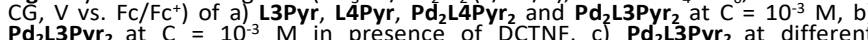
concentrations and d) the deconvoluted $\mathrm{CV}$ corresponding to (c).

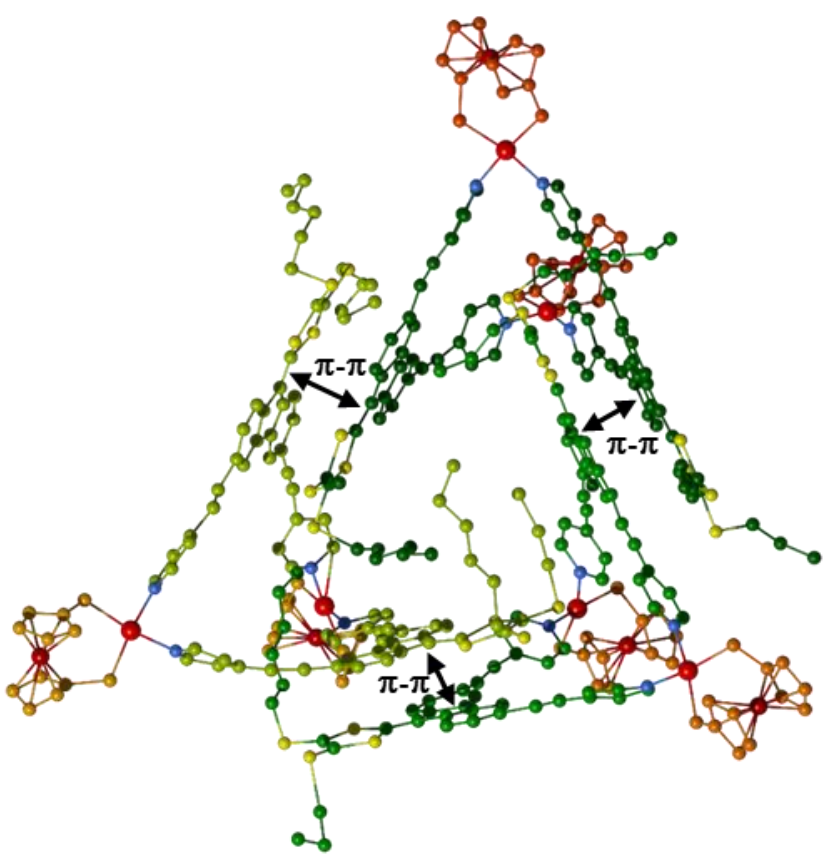

Fig. 4 Crystal packing of $\mathbf{P d}_{2} \mathbf{L}_{4} \mathbf{P y r}_{2}$ crystallized by slow diffusion of $\mathrm{MeOtBu}$ in a solution of $\mathrm{CHCl}_{3}$ containing 2 equiv. of DCTNF (dppf phenyl rings omitted for clarity).

observed for a DTF-based Ruthenium tweezer. ${ }^{33} \mathrm{As}$ expected, similar studies carried out with $\mathbf{P d}_{\mathbf{2}} \mathbf{L} \mathbf{4} \mathbf{P y r}_{\mathbf{2}}$ did not show any significant changes of the cyclic voltammogram, except a very weak anodic shift (Figure S6).

To get a better understanding of those interactions we tried to grow single crystals from solutions containing $\mathbf{P d}_{\mathbf{2}} \mathbf{L} \mathbf{4} \mathbf{P y r}_{\mathbf{2}}$ or $\mathbf{P d}_{\mathbf{2}} \mathrm{L}_{3} \mathrm{Pyr}_{\mathbf{2}}$ and DCTNF (2 equiv.). Even though all attempts to get cocrystallized structures were unsuccessful, vapor diffusion of MeOtBu into a mixture of $\mathbf{P d}_{\mathbf{2}} \mathbf{L} \mathbf{4} \mathbf{P y r}_{\mathbf{2}}$ and DCTNF lead to single crystals that does not show presence of DCTNF in the structure..$^{43-45}$ The latter exhibits a packing mode that differs from the one obtained in absence of DCNTF ${ }^{32}$ (Figures S8c) and shows some specific features (Figure 4). It includes three independent $M_{2} L_{2}$ metalla-clip units interacting through headto-tail $\pi-\pi$ stacking between their respective DTF units, with interplanar distances of ca. 3.5 $\AA$. As a result, they form an original discrete architecture constructed from two distinctive supramolecular interactions, i.e. coordination bonds and parallel displaced aromatic-aromatic interactions.

Deeper insights related to the interactions mode occurring between DCTNF and $\mathbf{P} \mathbf{d}_{\mathbf{2}} \mathbf{L} \mathbf{4} \mathbf{P y r}_{\mathbf{2}}$ or $\mathbf{P} \mathbf{d}_{\mathbf{2}} \mathbf{L} \mathbf{3} \mathbf{P y r}_{\mathbf{2}}$ were provided by UV-Vis experiments carried out in $\mathrm{CH}_{2} \mathrm{Cl}_{2}$ (Figure 5). Both metalla-clips show absorption spectra close to those of their constitutive ligands (L4Pyr and L3Pyr) with, as expected, molar extinction coefficients which are twice higher. They are characterized by two absorption bands at high energy localized around $300 \mathrm{~nm}$ which are ascribed to $\pi-\pi^{*}$ transitions located on the pyridine and flurorene units as well as an intense ICT 

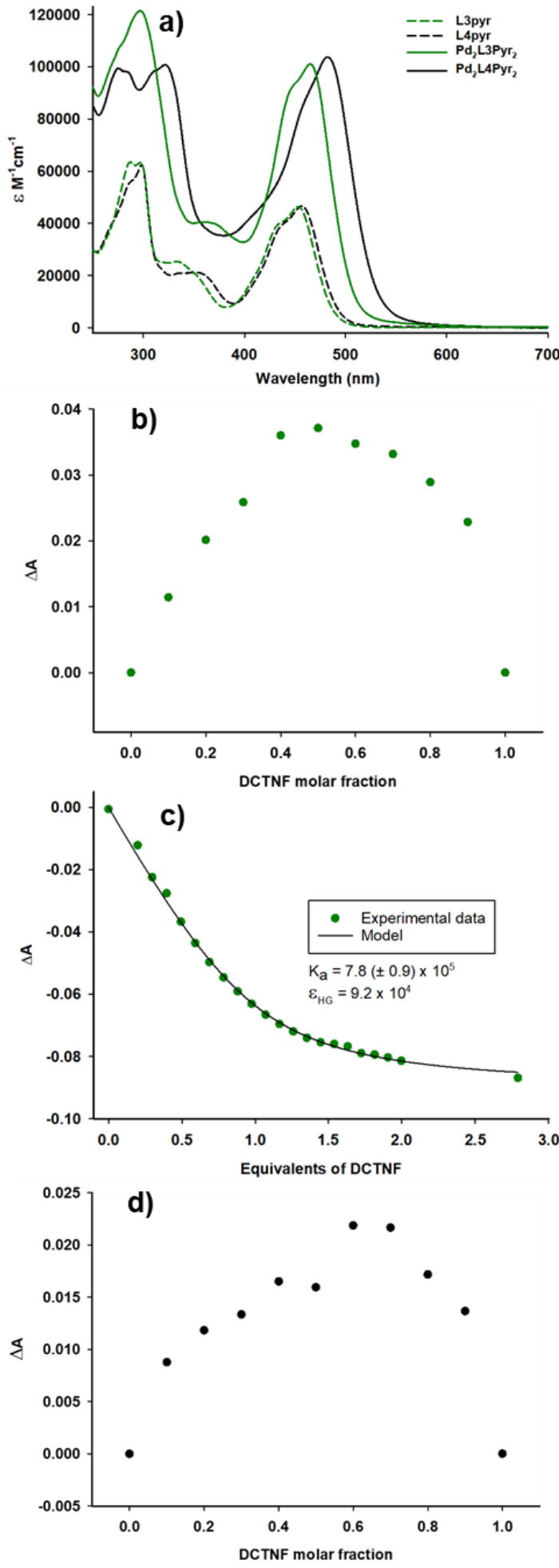

Fig. 5 UV-Vis spectra of ligands L3Pyr, L4Pyr and metalla-tweezers $\mathbf{P d}_{\mathbf{2}} \mathbf{L} \mathbf{2} \mathbf{P y r}_{2}$ and $\mathbf{P d}_{2} \mathbf{L} \mathbf{4} \mathbf{P y r}_{2}$ recorded in $\mathrm{CH}_{2} \mathrm{Cl}_{2}$ (a), Job plots for complexation of receptor $\mathbf{P d}_{2} \mathbf{L}_{3} \mathbf{P y r}_{2}$ (b) and $\mathbf{P d}_{2} \mathrm{LPPyr}_{2}$ (d) with DCNTF determined by UV-Vis spectroscopy respectively 465 and $480 \mathrm{~nm}\left(\mathrm{CH}_{2} \mathrm{Cl}_{2}, \mathrm{C}=10^{-5} \mathrm{M}\right)$, and plots of absorbance of a UV vis titration for complexation of receptor $\mathbf{P d}_{\mathbf{2}} \mathbf{L}_{3} \mathbf{P P y r}_{\mathbf{2}}\left(\mathrm{CH}_{2} \mathrm{Cl}_{2}, \mathrm{C}=10^{-5} \mathrm{M}\right)$ with DCNTF $\left(\mathrm{CH}_{2} \mathrm{Cl}_{2}, 5 \times 10^{-4} \mathrm{M}\right)$ at $465 \mathrm{~nm}$ (c)

band around $480 \mathrm{~nm}$ coming from the $\mathrm{HOMO}_{\mathrm{DTF}}-\mathrm{LUMO}_{\text {pyridine }}$ transition. ${ }^{46} \mathrm{Job}$ Plot experiments were carried out at $\lambda_{\max }=465$ $\mathrm{nm}\left(\mathbf{P d}_{\mathbf{2}} \mathbf{L} \mathbf{3} \mathbf{P y r}_{\mathbf{2}}\right.$, Figure $\left.\mathbf{5 b}\right)$ and $\mathbf{4 8 0} \mathrm{nm}\left(\mathbf{P d}_{\mathbf{2}} \mathbf{L} \mathbf{4} \mathbf{P y r} \mathbf{2}_{2}\right.$, Figure $\left.5 \mathrm{~d}\right)$, at $\mathrm{C}=10^{-5} \mathrm{M}$ in $\mathrm{CH}_{2} \mathrm{Cl}_{2}$, upon addition of aliquots of DCTNF ( $\mathrm{C}=5 \mathrm{x}$ $10^{-4} \mathrm{M}$ in $\mathrm{CH}_{2} \mathrm{Cl}_{2}$ ). As expected from $\mathrm{CV}$ experiments, both metalla-tweezers exhibit highly distinctive behaviors. As clearly seen from Figure $5 b$, a maximum is observed for a molar fraction of 0.5 in the Job plot titration of $\mathbf{P d}_{\mathbf{2}} \mathbf{L} \mathbf{3} \mathbf{P y y}_{\mathbf{2}}$ with DCTNF. This value is assigned to the formation of a 1:1 host-guest complex, for which both DTF unit cooperatively contribute to the guest binding, according to a sandwich-mode. A binding constant of $K_{a}=7.8( \pm 0.9) \times 10^{5}$ was calculated ${ }^{47}$, a value which illustrates the remarkable ability of this tweezer to complex the electro-deficient DCTNF unit. On the other hand, the Job plot titration in the case of $\mathbf{P d}_{\mathbf{2}} \mathbf{L} \mathbf{4} \mathbf{P y r}_{\mathbf{2}}$ (Figure $\mathbf{5 d}$ ) exhibits a maximum for $c a$. 0.6-0.7. This value correlates with a $1: 2$ stoichiometry, meaning that even though the metalla-assembly $\mathbf{P d}_{\mathbf{2}} \mathbf{L} \mathbf{4} \mathbf{P y r} \mathbf{r}_{\mathbf{2}}$ does not possess a cavity suitable for recognition of planar guests, it is able to interact with two DCTNF units. On this basis, we assume that each DTF fragment can interact independently with one DCTNF unit. This is corroborated by a ${ }^{1} \mathrm{H}$ NMR experiment, which shows that signals of a mixture of a DTF ligand and DCTNF, are shifted related to the species recorded alone (Figure S7).

\section{Conclusions}

In summary, the properties of two $\mathrm{M}_{2} \mathrm{~L}_{2}$ metalla-clips, $\mathbf{P d}_{\mathbf{2}} \mathbf{L} \mathbf{4} \mathbf{P y r}_{\mathbf{2}}$ and $\mathbf{P d}_{\mathbf{2}} \mathbf{L} \mathbf{3} \mathbf{P y r}_{\mathbf{2}}$, constructed from the same cis-blocked $\mathrm{Pd}(\mathrm{dppf})(\mathrm{OTf})_{2}$ complex and two isomeric DTF-based ligands differing by the position of the nitrogen atom on the pyridyl coordinating units, are compared. While the molecular tweezer built from L4Pyr shows an intramolecular distance of ca. $15 \AA$ between both redox-active tips, the one obtained from ligand L3Pyr features a cavity in which both DTF units are separated by $8.5 \AA$. The latter structural organization is favorable for promoting i) a tweezer dimerization upon oxidation, through formation of intercalated cationic dimeric species ii) formation of a host-guest complex with an electro-deficient DCTNF unit, with a remarkable association constant of $7.8 \times 10^{5}$ in methylene chloride. These results illustrate at which extent minor structural changes led on the starting ligand, may drastically impact the geometry and host properties of the resulting metalla-species prepared through a coordinationdriven self-assembled processes.

\section{Conflicts of interest}

There are no conflicts to declare

\section{Acknowledgements}

The authors gratefully acknowledge the French Embassy in Kiev (Ukr) for PhD grants (SK and MD). They also acknowledge the ASTRAL platform (SFR MATRIX, Univ. Angers) for their assistance in spectroscopic analyses. Finally, the financial support from the National FT-ICR network (FR 3624 CNRS) for conducting the research is gratefully acknowledged. 


\section{References}

1. T. R. Cook and P. J. Stang, Recent Developments in the Preparation and Chemistry of Metallacycles and Metallacages via Coordination, Chem. Rev., 2015, 115, 7001.

2. Y. Sun, C. Chen, J. Liu and P. J. Stang, Recent developments in the construction and applications of platinum-based metallacycles and metallacages via coordination, Chem. Soc. Rev., 2020, DOI: 10.1039/d0cs00038h.

3. R. Chakrabarty, P. S. Mukherjee and P. J. Stang Supramolecular coordination: self-assembly of finite twoand three-dimensional ensembles, Chem. Rev., 2011, 111, 6810 .

4. L.-J. Chen, J.-L. Zhu and H.-B. Yang, in Metallomacrocycles: From Structures to Applications, The Royal Society of Chemistry, 2019, pp. 77

5. L.-J. Chen, H.-B. Yang and M. Shionoya, Chiral metallosupramolecular architectures, Chem. Soc. Rev., 2017, 46, 2555.

6. M. Liu, L. Zhang and T. Wang, Supramolecular Chirality in Self-Assembled Systems, Chem. Rev., 2015, 115, 7304.

7. D. Bardhan and D. K. Chand, Palladium(II)-Based SelfAssembled Heteroleptic Coordination Architectures: A Growing Family, Chem. Eur. J., 2019, 25, 12241.

8. L. R. Holloway, P. M. Bogie and R. J. Hooley, Controlled selfsorting in self-assembled cage complexes, Dalton Trans., 2017.

9. W. M. Bloch and G. H. Clever, Integrative self-sorting of coordination cages based on 'naked' metal ions, Chem. Commun., 2017, 53, 8506.

10. Y. Lu, H.-N. Zhang and G.-X. Jin, Molecular Borromean Rings Based on Half-Sandwich Organometallic Rectangles, Acc. Chem. Res., 2018, 51, 2148.

11. S.-L. Huang, T. S. A. Hor and G.-X. Jin, Metallacyclic assembly of interlocked superstructures, Coord. Chem. Rev., 2017, 333, 1.

12. M. Frank, M. D. Johnstone and G. H. Clever, Interpenetrated Cage Structures, Chem. Eur. J., 2016, 22, 14104.

13. S. Zarra, D. M. Wood, D. A. Roberts and J. R. Nitschke, Molecular containers in complex chemical systems, Chem. Soc. Rev., 2015, 44, 419

14. V. Blanco, M. D. García, A. Terenzi, E. Pía, A. FernándezMato, C. Peinador and J. M. Quintela, Complexation and Extraction of PAHs to the Aqueous Phase with a Dinuclear PtIl Diazapyrenium-Based Metallacycle, Chem. Eur. J., 2010, 16, 12373

15. A. Casini, B. Woods and M. Wenzel, The Promise of SelfAssembled 3D Supramolecular Coordination Complexes for Biomedical Applications, Inorg. Chem., 2017, 56, 14715.

16. Y. Fang, J. A. Powell, E. Li, Q. Wang, Z. Perry, A. Kirchon, X. Yang, Z. Xiao, C. Zhu, L. Zhang, F. Huang and H.-C. Zhou, Catalytic reactions within the cavity of coordination cages, Chem. Soc. Rev., 2019, 48, 4707.

17. J. Guo, Y.-W. Xu, K. Li, L.-M. Xiao, S. Chen, K. Wu, X.-D. Chen, Y.-Z. Fan, J.-M. Liu and C.-Y. Su, Regio- and Enantioselective Photodimerization within the Confined Space of a Homochiral Ruthenium/Palladium Heterometallic Coordination Cage, Angew. Chem. Int., 2017, 56, 3852.

18. M. Yoshizawa, J. K. Klosterman and M. Fujita, Functional Molecular Flasks: New Properties and Reactions within
Discrete, Self-Assembled Hosts, Angew. Chem. Int. Ed., 2009, 48, 3418.

19. P. Mal, B. Breiner, K. Rissanen and J. R. Nitschke, White Phosphorus Is Air-Stable Within a Self-Assembled Tetrahedral Capsule, Science, 2009, 324, 1697.

20. T. Y. Kim, R. A. S. Vasdev, D. Preston and J. D. Crowley, Strategies for Reversible Guest Uptake and Release from Metallosupramolecular Architectures, Chem. Eur. J., 2018, 24, 14878.

21. A. Goswami, S. Saha, P. K. Biswas and M. Schmittel, (Nano)mechanical Motion Triggered by Metal Coordination: from Functional Devices to Networked Multicomponent Catalytic Machinery, Chem. Rev., 2020, 120, 125.

22. A. J. McConnell, C. S. Wood, P. P. Neelakandan and J. R. Nitschke, Stimuli-Responsive Metal-Ligand Assemblies, Chem. Rev., 2015, 115, 7729.

23. R.-J. Li, J. J. Holstein, W. G. Hiller, J. Andréasson and G. H. Clever, Mechanistic Interplay between Light Switching and Guest Binding in Photochromic [Pd2Dithienylethene4] Coordination Cages, J. Am. Chem. Soc., 2019, 141, 2097.

24. L.-J. Chen and H.-B. Yang, Construction of StimuliResponsive Functional Materials via Hierarchical SelfAssembly Involving Coordination Interactions, Acc. Chem. Res., 2018, 51, 2699.

25. S. Goeb, S. Bivaud, P. I. Dron, J.-Y. Balandier, M. Chas and M. Sallé, A BPTTF-based self-assembled electron-donating triangle capable of $\mathrm{C}_{60}$ binding, Chem. Commun., 2012, 48, 3106.

26. G. Szalóki, S. Krykun, V. Croué, M. Allain, Y. Morille, F. Aubriet, V. Carré, Z. Voitenko, S. Goeb and M. Sallé, RedoxDriven Transformation of a Discrete Molecular Cage into an Infinite 3D Coordination Polymer, Chem. Eur. J., 2018, 24, 11273.

G. Szalóki, V. Croué, V. Carré, F. Aubriet, O. Alévêque, E. Levillain, M. Allain, J. Arago, E. Orti, S. Goeb and M. Sallé, Controlling the Host-Guest Interaction Mode through a Redox Stimulus, Angew. Chem. Int. Ed., 2017, 56, 16272. G. Szalóki, V. Croué, M. Allain, S. Goeb and M. Sallé, Neutral versus polycationic coordination cages: a comparison regarding neutral guest inclusion, Chem. Commun., 2016, 52, 10012.

29. S. Goeb, S. Bivaud, V. Croué, V. Vajpayee, M. Allain and M. Sallé, A Self-Assembled Electro-Active $\mathrm{M}_{8} \mathrm{~L}_{4}$ Cage Based on Tetrathiafulvalene Ligands, Materials, 2014, 7, 611.

30. S. Bivaud, S. Goeb, V. Croué, P. I. Dron, M. Allain and M. Sallé, Self-Assembled Containers Based on Extended Tetrathiafulvalene, J. Am. Chem. Soc., 2013, 135, 10018.

31. S. Bivaud, J. Y. Balandier, M. Chas, M. Allain, S. Goeb and M. Sallé, A Metal-Directed Self-Assembled Electroactive Cage with Bis(pyrrolo)tetrathiafulvalene (BPTTF) Side Walls, J. Am. Chem. Soc., 2012, 134, 11968.

32. S. Krykun, M. Allain, V. Carré, F. Aubriet, Z. Voitenko, S. Goeb and M. Sallé, A M2L2 Redox-Active MetallaMacrocycle Based on Electron-Rich 9-(1,3-Dithiol-2ylidene)Fluorene, Inorganics, 2018, 6, 44.

33. S. Krykun, M. Dekhtiarenko, D. Canevet, V. Carre, F. Aubriet, E. Levillain, M. Allain, Z. Voitenko, M. Sallé and S. Goeb, Metalla-Assembled Electron-Rich Tweezers: RedoxControlled Guest Release Through Supramolecular Dimerization, Angew. Chem. Int. Ed., 2020, 59, 716. 
34. V. Croué, S. Krykun, M. Allain, Y. Morille, F. Aubriet, V. Carré, Z. Voitenko, S. Goeb and M. Sallé, A self-assembled M2L4 cage incorporating electron-rich 9-(1,3-dithiol-2ylidene)fluorene units, New J. Chem., 2017, 41, 3238.

35. D. F. Perepichka, I. F. Perepichka, O. Ivasenko, A. J. Moore, M. R. Bryce, L. G. Kuz'mina, A. S. Batsanov and N. I. Sokolov, Combining High Electron Affinity and Intramolecular Charge Transfer in 1,3-Dithiole-Nitrofluorene Push-Pull Diads, Chem. Eur. J., 2008, 14, 2757.

36. S. Amriou, C. Wang, A. S. Batsanov, M. R. Bryce, D. F. Perepichka, E. Ortí, R. Viruela, J. Vidal-Gancedo and C. Rovira, The Interplay of Inverted Redox Potentials and Aromaticity in the Oxidized States of New $\pi$-Electron Donors: 9-(1,3-Dithiol-2-ylidene)fluorene and 9-(1,3Dithiol-2-ylidene)thioxanthene Derivatives, Chem. Eur. J., 2006, 12, 3389.

37. A. Macchioni, G. Ciancaleoni, C. Zuccaccia and D. Zuccaccia, Determining accurate molecular sizes in solution through NMR diffusion spectroscopy, Chem. Soc. Rev., 2008, 37, 479.

38. L. Avram and Y. Cohen, Diffusion NMR of molecular cages and capsules, Chem. Soc. Rev., 2015, 44, 586.

39. M. Ferrer, A. Gutiérrez, L. Rodríguez, O. Rossell, E. Ruiz, M. Engeser, Y. Lorenz, R. Schilling, P. Gómez-Sal and A. Martín, Self-Assembly of Heterometallic Metallomacrocycles via Ditopic Fluoroaryl Gold(I) Organometallic Metalloligands, Organometallics, 2012, 31, 1533.

40. Y. Cotelle, M. Hardouin-Lerouge, S. Legoupy, O. Alévêque, E. Levillain and P. Hudhomme, Glycoluriltetrathiafulvalene molecular clips: on the influence of electronic and spatial properties for binding neutral accepting guests, Beilstein J. Org. Chem., 2015, 11, 1023.

41. J. Leblond and A. Petitjean, Molecular Tweezers: Concepts and Applications, Chemphyschem, 2011, 12, 1043.

42. M. Hardouin-Lerouge, P. Hudhomme and M. Sallé, Molecular clips and tweezers hosting neutral guests, Chem. Soc. Rev., 2011, 40, 30.

43. A. G. Shtukenberg, M. D. Ward and B. Kahr, Crystal Growth with Macromolecular Additives, Chem. Rev., 2017, 117, 14042.

44. A. G. Shtukenberg, S. S. Lee, B. Kahr and M. D. Ward, Manipulating Crystallization with Molecular Additives, Annu. Rev. Chem. Biomol. Eng., 2014, 5, 77.

45. F. Jones and M. I. Ogden, Controlling crystal growth with modifiers, Crystengcomm, 2010, 12, 1016.

46. Z. Niu, D. Li, D. Liu, D. Xia, Y. Zou, W. Sun and G. Li, Syntheses, electrochemical behaviors, spectral properties and DFT calculations of two 1,3-dithiole derivatives, Chem. Res. Chin. Univ. , 2014, 30, 425.

47. D. Canevet, M. Gallego, H. Isla, A. de Juan, E. M. Perez and N. Martin, Macrocyclic Hosts for Fullerenes: Extreme Changes in Binding Abilities with Small Structural Variations, J. Am. Chem. Soc., 2011, 133, 3184. 